\title{
Analysis of Catchment Evapotranspiration at Different Scales Using Bottom-up and Top-down Approaches
}

\author{
Xiangyu $\mathrm{Xu}$ and Dawen Yang \\ State Key Laboratory Of Hydroscience and Engineering, Tsinghua University
}

China

\section{Introduction}

Evapotranspiration is a highly non-linear process in catchment hydrological cycle, and simulation of the evapotranspiration process is a major component of physically-based hydrological models. Most process-based hydrological models estimate actual evapotranspiration following the Penman's approach (Penman, 1948; Allen et al., 1998) by reducing potential evapotranspiration to actual evapotranspiration in response to water stress which is given by a function of soil water availability for a given vegetation condition. The soil water availability is governed by other hydrological processes such as infiltration and soil moisture redistribution (both vertically and laterally). Physically-based hydrological model predict the catchment water balance through detailed simulation of hydrological processes at small temporal and spatial scales. However, catchment annual evapotranspiration can be easily and simply predicted using lumped conceptual models such as Fu's model based on the Budyko hypothesis (Yang et al., 2007). Combination of these bottom-up and top-down approaches can help understand the dominant control on catchment evapotranspiration at different time scales.

The top-down approach in hydrology was first introduced by Klemes (1983) and extended further by Sivapalan and coworkers as outlined in Sivapalan et al. (2003). This approach was used to investigate the hydrological response at long temporal scale and large spatial scale (e.g. an annual time and watershed scale) and progressively narrowing down to processes at smaller scales (e.g. hourly time and hillslope scale). The major advantage of the top-down approach is that it can reduce data requirements and limit model complexity (Littlewood et al., 2003). The lumped conceptual model is a typical example. A simple lumped model can be easily used for hypothesis testing and as the starting point for developing a new generation of models. Many researchers carried out a series of studies using the top-down approach (Klemes, 1983; Jothityangkoon et al., 2001; Atkinson et al., 2002, 2003; Farmer et al., 2003; Eder et al., 2003; Son and Sivapalan, 2007; Zhang et al., 2008), and developed a collection of lumped conceptual models for simulating water balance responses across different temporal scales (annual, monthly and daily) in different watersheds located in different climatic regimes. Budyko (1974) proposed a semi-empirical relationship between the ratio of annual evapotranspiration to annual precipitation and the ratio of annual precipitation to annual net radiation. Considerable research has been performed on the 
Budyko curve (Fu, 1981; Milly, 1994; Choudhury, 1999; Wolock and McCabe, 1999; Zhang et al., 2004, Yang et al., 2008a) through analyzing the interactions between climate, soils and vegetation in producing annual water balance. A simple water-energy balance equation (Yang et al., 2006 and 2007) based on the Budyko hypothesis (1974) has been used for predicting the long-term average evapotranspiration and the inter-annual variability of evapotranspiration. The top-down approach is usually used for explaining the observed responses at the watershed scale, in which one problem is how to generalize the catchment hydrological pattern and whether the hypothesis of conceptualization is reasonable. Another problem is how to explain the interactions between the response at watershed scale and the processes that contributed to it that occur at smaller scales. The top-down approach has not been widely used in hydrological prediction, but as Sivapalan (2003) mentioned this approach should become an important component of the toolkit for data analysis and hydrological model development.

The bottom-up approach in hydrology generally uses "process based" or "physically based" distributed hydrological models, which can predict overall catchment's water balance components based on process simulation at smaller spatial and temporal scales. In order to understand the hydrological processes at a local scale and to analyze the temporal and spatial variability of water resources at a watershed scale, a number of distributed hydrological models have been developed: SHE model (Beven et al., 1980; Abbott et al., 1986; Bathurst et al., 1995; Refsgaard and Storm, 1995), IHDM model (Morris, 1980), SLURP model (Kite, 1995), SWAT model (Arnold et al., 1998), GBHM model (Yang et al., 1998, 2002, 2004; Cong et al., 2009), WEP (Jia et al., 2001), VIC (Liang, 1994) etc. These and many other models have been developed and have been applied to interpret and predict the impacts of land-use change and climate variability. A bottom-up model requires vast amounts of input data for describing the variable rainfall and evapotranspiration fields, topography, vegetation, soil, and other land surface conditions, and also needs dozens of parameters for representation of the hydrological processes. Therefore, in the one hand, the costs would be prohibitively high. Beven (2001) discussed the problems of distributed model including the problem of nonlinearity, scale, equifinality, uniqueness and uncertainty. Because the physically-based distributed hydrological models can offer both detailed information of hydrological processes inside a catchment and general catchment hydrological pattern, this kind of models are usually used to analyze hydrological impacts of the changes of land use and climate.

Most recently there are discussions on the direction of hydrological research, which focus on either estimating predictive uncertainty or understanding catchment hydrological function (Beven, 2006; Sivakumar, 2008; Sivapalan, 2009). For better understanding of catchment hydrology, we need a change in the methodology of hydrological analysis. Though both the bottom-up and the top-down approaches are widely used in catchment hydrology, very little research has been carried out on the linkage between these two methods. Klemes (1983) first suggested the combination of these two approaches and mentioned that "the most promising route to significant new discoveries in hydrology is to combine the upward and downward research based on the existing facts and knowledge as well as on imagination and intuition, to form testable hypotheses-i.e. to apply the time-honored scientific method". Sivapalan et al. (2003) also anticipated that "in the near future, studies that address the same problem by both approaches at the same time will make a significant impact on a better understanding of hydrologic prediction issues". Based on the previous research, this chapter attempts to build the connection between the top-down and bottom- 
up approach and to understand the dominant factors on catchment evapotranspiration at different time scales using a distributed physically-based hydrological model and a simple water-energy balance model.

\section{Study area and data availability}

The Luan River basin is located in the region delimited by geographical coordinates $40.4^{\circ}$ $42.6^{\circ} \mathrm{N}$ and $115.5^{\circ}-118.9^{\circ} \mathrm{E}$ with the elevation ranging about $150-2000 \mathrm{~m}$ above the sea level. The Panjiakou Reservoir is the largest reservoir on the Luan River in northern China, the upstream watershed of the Panjiakou Reservoir is selected as the study area in the present research (see Fig. 1).

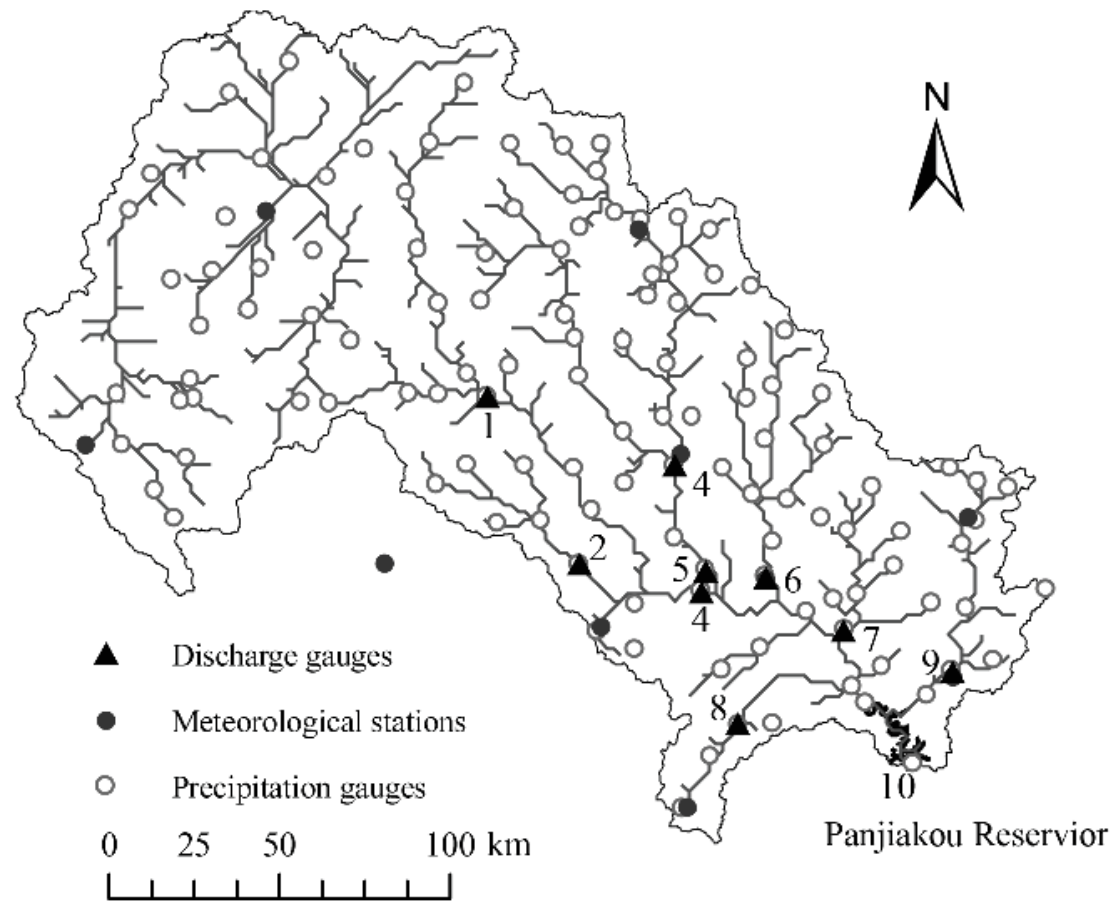

Fig. 1. The study area.

The catchment extent and topography are represented using the digital elevation model (DEM) of a $90 \mathrm{~m}$ resolutionwhich is obtained from the global topography database (http://telascience.sdsc.edu/tela_data/SRTM/version2/SRTM3/). Land use map of 100m resolution was from Data Center for Resources and Environmental Sciences of Chinese Academy of Sciences. Based on the available data, the land use has been regrouped into 7 categories including water body, urban area, forest, irrigated cropland, upland, grassland and shrub for the study area. Seasonal change of vegetation is expressed by the monthly leaf area index (LAI) derived from monthly NDVI (NDVI data is obtained from the DAAC website of GSFC/NASA: http://daac.gsfc.nasa.gov/DAAC_DOCS/). The soil type used here is obtained from the FAO-UNESCO's 1:5 million scale Soil Map of the World (FAO, 
2003). The soil properties used for the hydrological simulation including the porosity, the saturated hydraulic conductivity and the other soil water parameters corresponding to each soil type in this map are obtained from the Global Soil Data Task (IGBP-DIS, 2000) with an 8-km resolution.

Daily meteorological data are obtained from China Meteorological Administration and additional daily precipitation data are obtained from the Ministry of Water Resources. The daily meteorological data consists of precipitation, temperature, average wind speed, relative humidity, sunshine duration, etc. There are 10 meteorological stations and 121 precipitation gauges in this region (see Fig. 1). From the two data sets, a time period from 1980 to 1991 is selected according to the availability of records in these meteorological stations and precipitation gauges. The gridded meteorological data required as input to the distributed hydrological model is interpolated from the gauge data. Precipitation is interpolated using an angular-distance weighting method (New, et al., 2000). In the same way, the wind speed, relative humidity and sunshine hours are also interpolated into each grid. The temperatures (maximum, minimum and mean) are interpolated using an elevation-corrected angulardirection weighting method. The daily potential evapotranspiration is calculated using the wind speed, relative humidity, sunshine hours and temperature (Shuttleworth, 1993).

The discharge data are collected for the same period of 1980-1991 from the "Hydrological Year Book" published by the Hydrological Bureau of the Ministry of Water Resources. In this study, seven gauges located on the tributaries and two gauges located on the mainstream (see Fig. 1) are selected for analysis.

\section{Methodology}

The ratio of evapotranspiration to precipitation in the study area is nearly $70 \sim 80 \%$, therefore, estimation of evapotranspiration is important for understanding the catchment water balance. The physically based hydrological model can estimate hourly evapotranspiration at hillslope scale, and through a bottom-up analysis the hourly evapotranspiration in each hillslope can be integrated into daily, monthly, annual and longterm mean annual evapotranspiration at catchment scale, which offers a reference for the top-down analysis. The long-term mean annual evapotranspiration of a catchment can be estimated using a water-energy balance model first, and through a top-down analysis the temporal scale is downward to year, month and day for identifying the dominant factors on catchment evapotranspiration at different time scales.

\subsection{The distributed hydrological model-GBHM model}

Since the GBHM model has been successfully applied in the Yellow River (Yang et al., 2004; Cong et al., 2009) and the Yangtze River (Xu et al., 2007, 2008), it is chosen as a bottom-up tool to simulate the hydrological processes and the evapotranspiration in the Luan River basin. As shown in Fig. 2, 2-km grid is used for discretization of the study catchment, in which a sub-grid parameterization scheme is employed to represent the hillslope topography (Yang et al., 2002). The procedures of model construction contain catchment subdivision, sub-grid parameterization, physically-based hydrological simulation on hillslope and kinematic wave flow routing.

A total of 97 sub-catchments were divided for the study catchment. For each sub-catchment, the geomorphologic property of stream-hillslope formation is used for representing the catchment topography and it is also assumed that a large grid is comprised of a set of 
hillslopes located along the streams. From a macro-scale viewpoint, the hillslopes located in a grid are viewed as being geometrically similar. A hillslope with a unit width is called a hillslope element, represented by a rectangular inclined plane (Fig. 2).

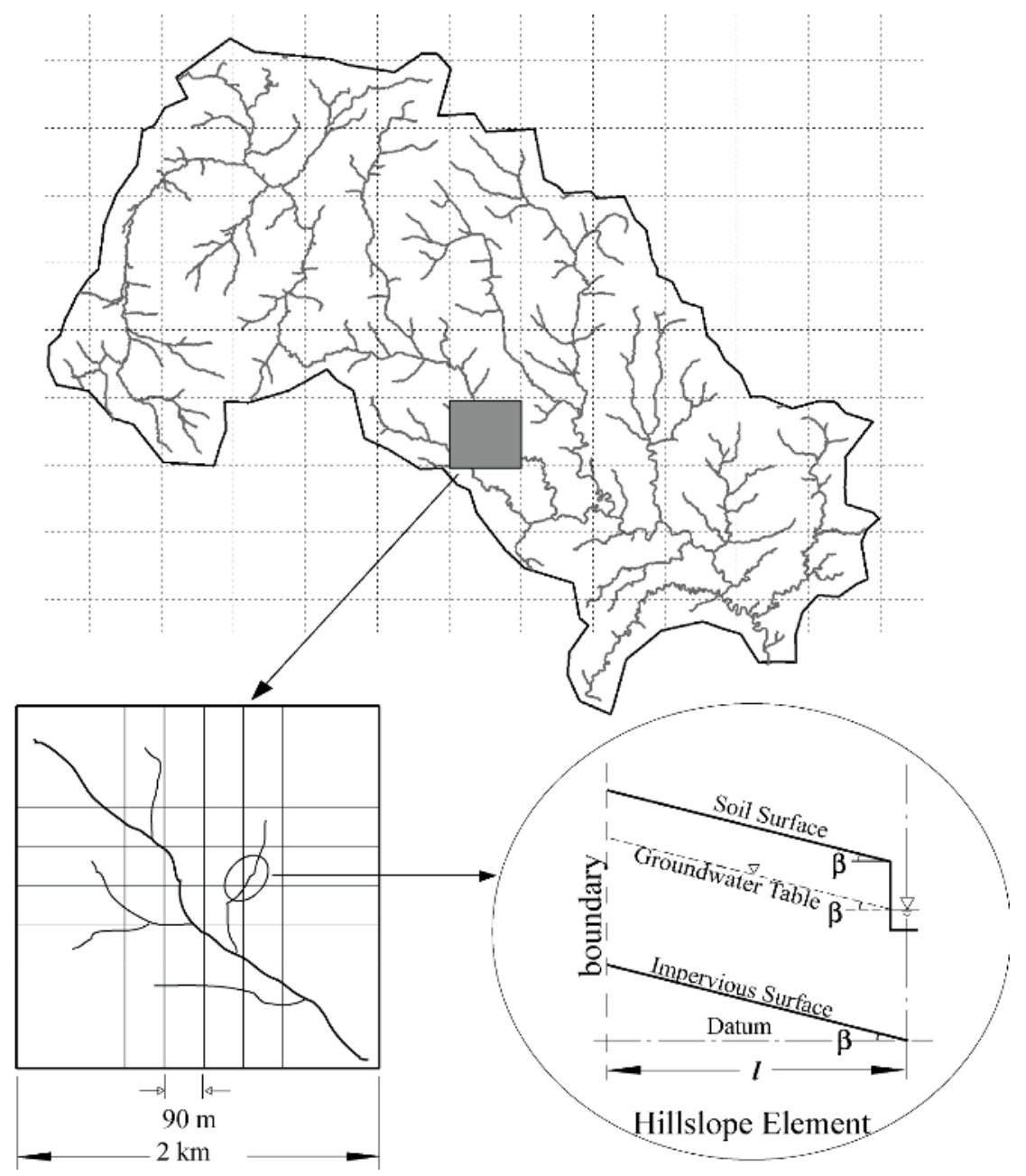

Fig. 2. Structure of the GBHM model.

Considering the land cover heterogeneity, hillslopes located in a 2-km grid are grouped. The soil within a grid is represented as a single dominant soil type. The runoff generated from one grid is the sum of surface and subsurface runoff. The vertical flux, the actual evapotranspiration, is the total evapotranspiration simulated from all of the hillslopes. The soil moisture content is taken as the area-averaged soil moisture of all the hillslopes.

The hydrological processes included in the GBHM model are snowmelt, canopy interception, evapotranspiration, infiltration, surface flow, subsurface flow and the exchange between the groundwater and the river (Yang et al., 1998, 2002 and 2004), which 
are simulated at 1-hour time step. Actual evapotranspiration is estimated from potential evapotranspiration, which is calculated by the Penman equation (Penman, 1984). Considering seasonal variation of LAI, root distribution and soil moisture availability, it is computed individually from the canopy water storage, root zone and soil surface. For each 1-hour time step, actual evaporation rate from the canopy storage is expressed as:

$$
E_{\text {canopy }}=K_{c} E_{p}
$$

where $E_{p}$ is the potential evaporation rate and is the crop coefficient. The vegetation transpiration rate is estimated as the rate of water taken up from the root zone and follows the equation:

$$
E_{\mathrm{tr}}\left(z_{j}\right)=K_{c} E_{p} f_{1}\left(z_{j}\right) f_{2}\left(\theta_{j}\right) \frac{L A I}{L A I_{0}}
$$

where $E_{\mathrm{tr}}\left(z_{j}\right)$ is the transpiration rate from layer $\mathrm{j}$ of the root zone; $f_{1}\left(z_{j}\right)$ is the root distribution function that is given by a triangular distribution with its maximum near the surface; $f_{2}\left(\theta_{j}\right)$ is given as a linear function of soil moisture $\theta_{j}$; and $L A I_{0}$ is the maximum leaf area index of the vegetation in a year. For the bare soil, the evaporation rate is given by:

$$
E_{s}=K_{c} E_{p} f_{2}(\theta)
$$

where $K_{c}$ is the evaporation rate from the soil surface. In ponding conditions, the value of $K_{c}$ is 1 . The actual transpiration from the root zone and evaporation from the soil surface are treated as sink terms in Richards' equation that is employed to model soil water movement in the unsaturated zone.

Infiltration and subsurface flow in the vertical direction and along the hillslope are described in a quasi-two-dimensional subsurface model. The vertical water flow in the topsoil is represented by Richards' equation. The soil water distribution along the hillslope is treated as uniform. When the soil water content in each layer is more than the field capacity, water moves to the stream along the hillslope by gravity.

The surface runoff, from the infiltration excess and saturation excess, is obtained by solving Richards' equation and flows to the river along the hillslope by a kinematic wave. The groundwater aquifer is treated as an individual storage corresponding to each grid. The exchange between the groundwater and the river water is considered as steady flow and is calculated by Darcy's law (Yang et al., 2002). The runoff generated from the grid is the lateral inflow into the river at the same flow interval. Flow routing in the river network is solved using the kinematic wave approach.

The parameters used in the model include vegetation parameters, land surface parameters, soil-water properties, river parameters, a snow-melting parameter and a groundwater parameter. Since most parameters have their physical meanings, they can be estimated through field tests. This study specifies the parameters by referring to the existing database and handbooks. A 6-year test run from 1980 to 1985 is carried out for calibrating the model parameters. One of the calibrated parameters in this model is the snowmelt factor in the temperature-based snowmelt equation. Another calibrated parameter, the hydraulic conductivity of the groundwater, is calibrated by checking the base flow in different subbasins. Model validation is carried out from 1986 to 1991. In the calibration period, the 
Nash-Sutcliffe coefficient for the simulated daily discharges at the outlet of the study area is nearly 0.80 , and the absolute values of the relative error are less than $2 \%$. For the major tributaries, the values of are larger than 0.65 and the absolute values of the relative error are less than $8 \%$ and the others are more than $10 \%$. This showed that hydrological simulation by the GBHM model is reasonable.

\subsection{The water-energy balance model}

Evapotranspiration is the key component linking water balance with energy balance. The primary factors controlling the long-term mean evapotranspiration are the local interaction of water supply (precipitation) and demand (potential evapotranspiration). Budyko (1974) assumed that actual evapotranspiration is controlled by both water and energy availabilities and considered that the ratio of annual evapotranspiration and annual precipitation is the function of the ratio of annual precipitation and annual net radiation. Based on the Budyko hypothesis, and based on dimensional analysis and mathematical reasoning, Yang et al. (2008a) considered the important effect of the vegetation and derived an analytical equation of the coupled water-energy balance at an annual time scale, expressed as:

$$
E=\frac{E_{0} P}{\left(P^{n}+E_{0}^{n}\right)^{1 / n}}
$$

where the parameter $n$ represents the effect of the catchment landscape characteristics, such as vegetation, soil properties and slope gradient. This theoretical equation has also been extended to a variety of time scales.

In order to consider the effect of the vegetation, Yang et al. (2009) changed the relative soil water storage $S_{\max } / E_{0}$ in the parameter $\varpi$ to vegetation coverage $M$ in the parameter $n$. The empirical formula of parameter $n$ is given for the Haihe River basin as:

$$
n=2.721\left(\frac{K_{s}}{i_{r}}\right)^{-0.393} M^{-0.301} \exp (4.351 \tan \beta)
$$

where the monthly vegetation coverage was calculated from the NDVI data by using the method proposed by Gutman and Ignatov (1998):

$$
M=\left(N D V I-N D V I_{\min }\right) /\left(N D V I_{\max }-N D V I_{\min }\right)
$$

The actual evapotranspiration obtained from Eqs. (4) and (5) showed remarkable agreement with that derived from the long-term water balance at Haihe River Basin (Yang et al., 2009), so Eqs. (4) and (5) were used in this research to calculate the actual annual evapotranspiration. In order to validate the water-energy balance model given by Eqs. (4) and (5) at annual time scale, the actual annual evapotranspiration simulated for each subcatchment were plotted against the actual annual evapotranspiration estimated from the observed precipitation subtracting the observed runoff by neglecting the change of water storage (see Fig. 3). Most values of predicted annual evapotranspiration are much close to the observed ones, which shows good simulation of annual evapotranspiration. The relative error between the long-term average evapotranspiration calculated by this model and the actual evapotranspiration estimated from the long-term water balance is less than $5 \%$. 


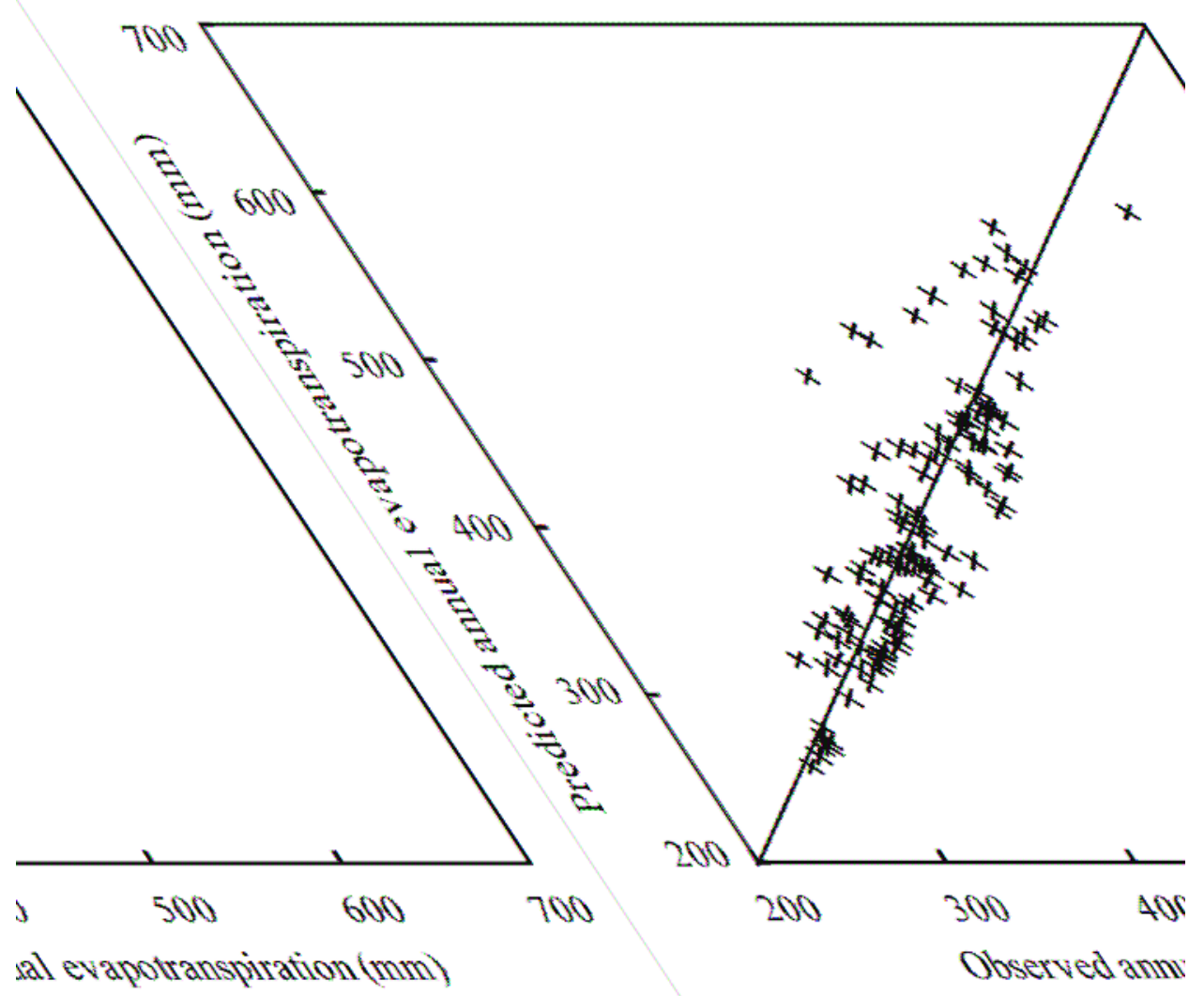

Fig. 3. Predicted value of annual evapotranspiration by the water-energy balance model plotting versus observed one (the 1:1 line is plotted for comparison).

As Eq. (4) doesn't consider inter-annual variability of soil water content, Yang et al. (2008b) derived another equation to estimate the evapotranspiration at arbitrary time scale which contains the variability of soil water, followed as:

$$
E=E_{0}(P+S) /\left((P+S)^{n}+E_{0}^{n}\right)^{1 / n}
$$

in which $P$ is the precipitation, and $S$ is the initial soil water of each simulation time period (i.e., annual, monthly, daily period).

To use the above equation for continuous simulation, we rewrite Eq. (7) as:

$$
E_{i}=E_{0, i}\left(P_{i}+S_{i-1}\right) /\left(\left(P_{i}+S_{i-1}\right)^{n}+E_{0, i}^{n}\right)^{1 / n}
$$

in which $i$ represents the ith simulation time period, $S_{i-1}$ represents the initial soil water content at the ith period. And the soil water content at the end of the ith period can be derived from the water balance equation as: 


$$
S_{i}=P_{i}+G_{i}-R_{i}-E_{i}+S_{i-1}
$$

in which $G_{i}$ is the groundwater recharge. The value of $G_{i}$ is ignored since its relatively small value in the research area.

The evaportranspiration at arbitrary time scales can be simulated using Eqs. (8) and (9) as long as the initial soil water content $S_{0}$ is given. The value of $S_{0}$ is derived from the continuous simulation at the first several simulation periods. The parameter $n$ in Eq. (8) is calculated at different time scale according to Eq. (5), however, at the daily time scale the same parameter as the monthly scale is used due to the vegetation data availability.

\section{Results and discussion}

\subsection{Bottom-up analysis}

The GBHM model used a linear assumption at hourly temporal and hillslope spatial scale, that is, the actual evapotranspiration for a hydrological unit at hourly scale is estimated to be proportional to the potential evapotranspiration (Eqs. (1) - (3)). It is known that annual precipitation, potential and actual evapotranspiration are following the Budyko curve at catchment scale. Based the long-term evapotranspiration estimated by GBHM, Fig. 4 plots the annual precipitation, potential and actual evapotranspiration for the 9 sub-catchments and the whole watershed in two alternative forms of the Budyko curves, i.e. $E / P$ vs. $E_{0} / P$ and $E / E_{0}$ vs. $P / E_{0}$. The value of parameter ranges from 2.5 to 2.95 in the study area and all the points stand inside the two curves.
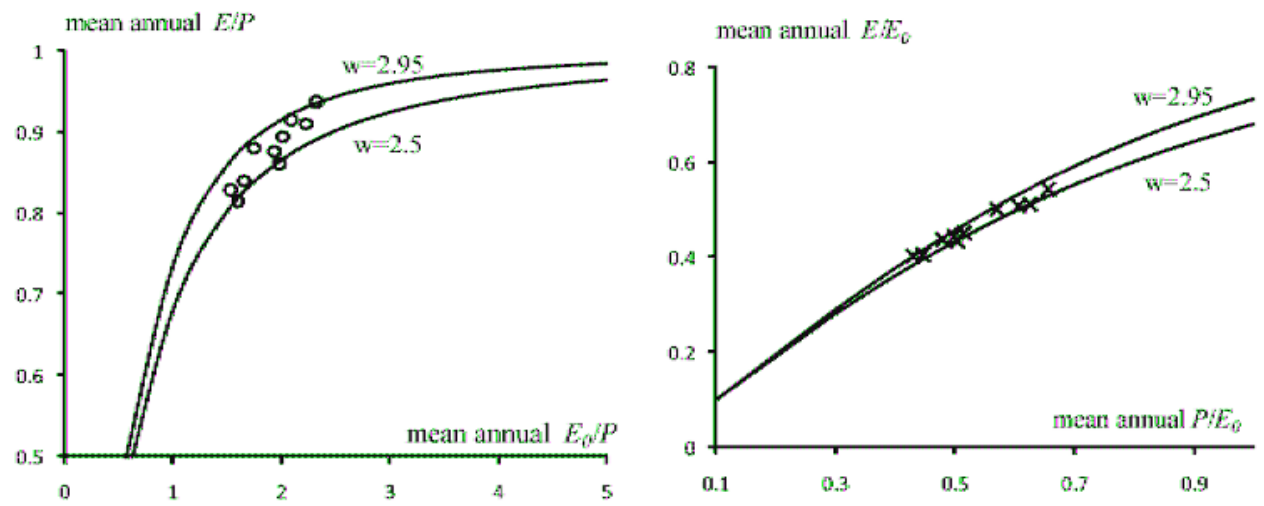

Fig. 4. Long-term mean values of annual actual evapotranspiration, precipitation, and potential evapotranspiration for the 10 sub-catchments are plotted in two different but equivalent Budyko-type forms (plotted in scattering points) together with the Budyko curves with the regional average values of parameter $\varpi$.

According to Yang et al.'s study (Yang et al., 2006), the actual evapotranspiration at annual and catchment scale is mainly controlled by precipitation rather than potential evapotranspiration in the non-humid regions of China, and the relationship between the actual and potential evapotranspiration should be complementary. The actual and potential evapotranspiration is usually plotted against the precipitation for validating the complementary relationship of evapotranspiration. Fig. 5 shows the complementary relationship between the actual and potential evapotranspiration, in which the actual 

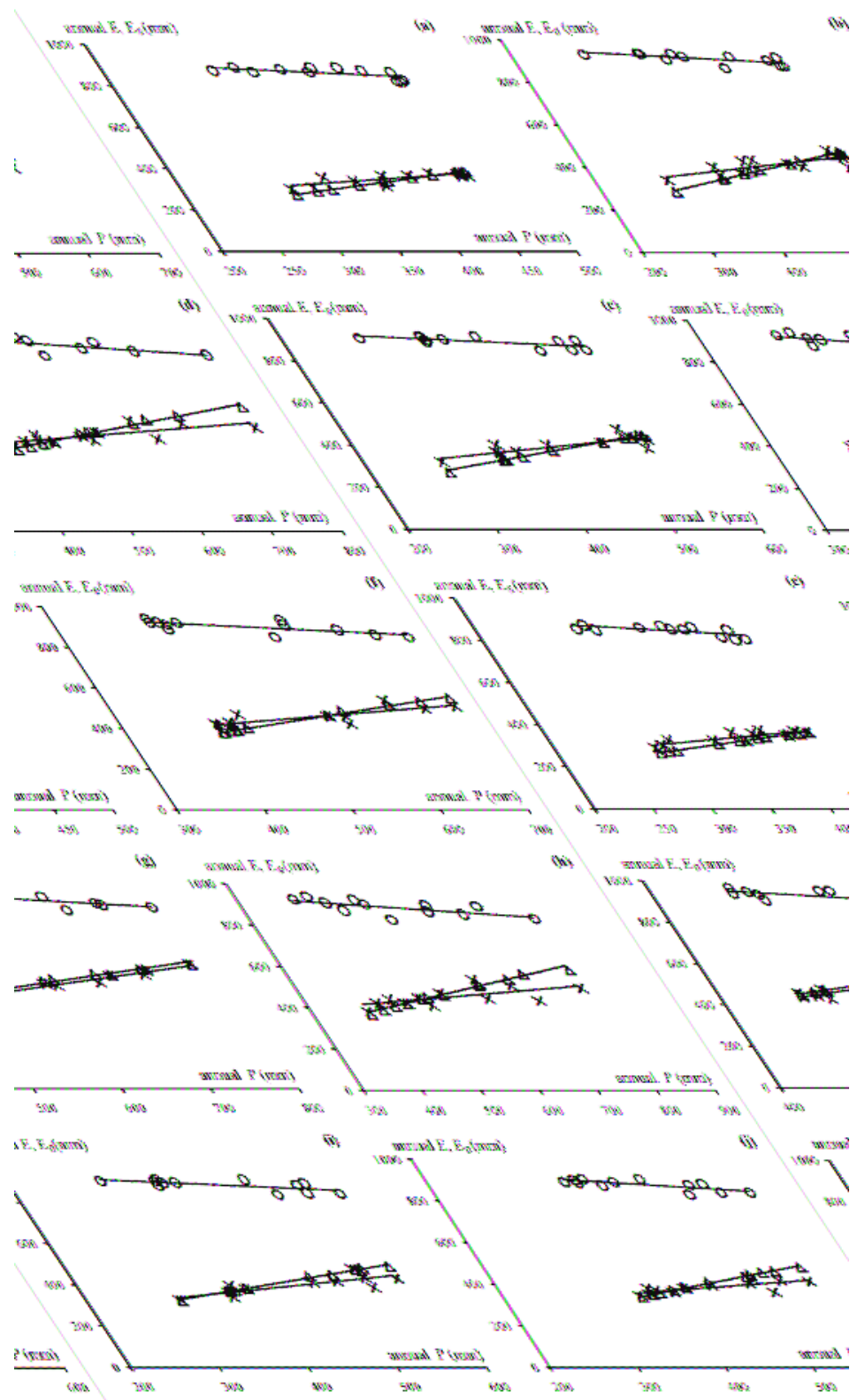

Fig. 5. Relationship between annual values of actual evapotranspiration $(E)$ and potential evapotranspiration $\left(E_{0}\right)$ plotted versus annual precipitation $(P)$ : (a)-(i) represent the 9 subcatchment, respectively, and (j) represents the whole study catchment. (The circular dots represent potential evapotranspiration $\left(E_{0}\right)$, the cross dots represent actual annual evapotranspiration $(E)$ predicted by GBHM, and the triangular dots represent actual annual evapotranspiration $(E)$ predicted by water-energy balance model) 
evapotranspiration is simulated by the GBHM. From Fig. 4 and 5, it is known that annual catchment evapotranspiration simulated by the GBHM agreed with the Budyko curve and followed the complementary relationship with potential evapotranspiration, which showed that the GBHM could simulate interaction between the land surface and atmosphere.

For a general case, the actual evapotranspiration is determined mainly by the potential evapotranspiration, soil moisture and vegetation status, which can be expressed in a general form as $E=f\left(E_{0}, \theta\right.$, vegetation $)(\theta$ is soil moisture content). This is an unknown non-linear equation for the most cases in a real catchment. One analytical solution of this equation is given as Eq. (4) which shows a nonlinear relationship between the annual precipitation, potential and actual evaportranspiration. This equation can also be calculated as the summation of the actual evapotranspiration at each 1-hour time step over the same year. At hourly time scale over a uniform landscape condition, the soil moisture can be viewed as constant and expressed as a soil moisture-impact factor (that is expressed as a stage-linear function of soil moisture content) in the equation; and the leaf-area-index can also viewed as constant and expressed as a vegetation-impact factor. Therefore, the linear assumption (Eqs. (1)- (3)) for a hydrological unit with relative uniform landscape condition at a short time scale (1-hour in this model) can be adopted.

The complementary relationship between the actual and potential evapotranspiration results from the interaction between the land surface and atmosphere. For a given net radiation, a decrease in actual evapotranspiration will cause an increase in sensible heat flux, and then an increase in potential evapotranspiration due to the land surface-atmosphere interactions (Bouchet, 1963). Budyko (1974) assumed that actual evapotranspiration is controlled by both water and energy availabilities. At the annual time scale, the water availability is the amount of annual precipitation and the energy availability can be measured by the potential evapotranspiration. The water-energy balance given by Eq. (4) describes the non-linear relationship among annual precipitation, potential and actual evapotranspiration and the land surface-atmosphere interactions. In the GBHM, the potential evapotranspiration rate is estimated using Penman's equation based on the daily meteorological data, which is the synthesized result of net radiation and turbulent diffusion including the feedback from land surface (e.g. the vapor pressure and air temperature are affected by the land surface evapotranspiration). Therefore, the actual evapotranspiration simulated by the GBHM model also includes the interaction and feedback between land surface and atmosphere.

\subsection{Top-down analysis}

A lumped water-energy balance model is used in the top-down analysis for understanding the major controlling factors of the evapotranspiration at different temporal scales. The actual evapotranspiration simulated by the GBHM was used as a reference for this analysis. Analysis is from a long-term time scale down to an annual, monthly and daily time scale. At the long-term time scale, Eq. (4) is used to estimate the actual evapotranspiration; at the annual time scale, Eq. (4) is used to estimate the actual evapotranspiration neglecting of the inter-annual variability of soil moisture; at the monthly and daily time scale, Eq. (8) is used with consideration of the soil moisture availability.

\section{Actual evapotranspiration at long-term time scale}

The mean annual evapotranspiration is controlled by the local interaction of fluctuating water supply (precipitation) and demand (potential evapotranspiration) at long-term time scale. Fig. 6 and Table 1 show the comparison of the long-term mean values of actual 


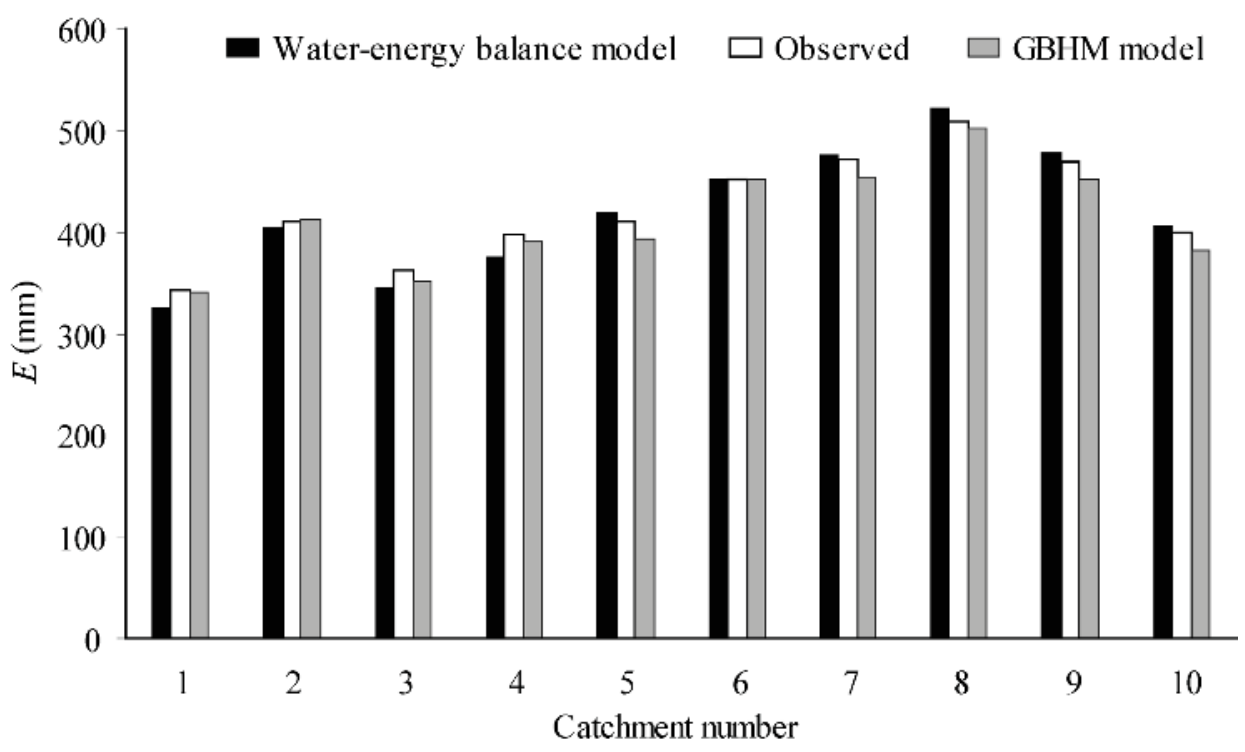

Fig. 6. Comparison of the long-term average evapotranspiration estimated by water-energy balance model, GBHM model and from the observed data. (number 1-9 represents the subcatchment of the upstream of the Guojiatun station, Boluonuo station, Sandaohezi station, Xiahenan station, Hanjiaying station, Chengde station, Xiabancheng station, Liying station, Kuancheng station, respectively and number 10 represents the whole watershed).

\begin{tabular}{|c|c|c|c|c|c|c|c|c|c|}
\hline \multirow[t]{2}{*}{ No. } & \multirow[t]{2}{*}{ Guage } & \multirow[t]{2}{*}{ River } & \multirow[t]{2}{*}{$P(\mathrm{~mm})$} & \multirow[t]{2}{*}{$R(\mathrm{~mm})$} & \multicolumn{3}{|c|}{$\begin{array}{l}\text { Simulated actual } E \\
(\mathrm{~mm})\end{array}$} & \multicolumn{2}{|c|}{$\begin{array}{c}\text { Relative error } \\
\text { RE (\%) }\end{array}$} \\
\hline & & & & & $\overline{E_{w b}}$ & $E_{\text {webm }}$ & $E_{g b h m}$ & $R E_{1}$ & $R E_{2}$ \\
\hline 1 & Guojiatun & Luan River & 356.8 & 21.7 & 335.1 & 319.3 & 340.7 & -4.72 & 1.67 \\
\hline 2 & Boluonuo & Xingzhou & 453.1 & 59.8 & 393.2 & 393.3 & 411.5 & 0.00 & 4.63 \\
\hline 3 & Sandaohezi & Luan & 375.5 & 23.8 & 351.7 & 336.6 & 351.5 & -4.29 & -0.07 \\
\hline 4 & Xiahenan & Yimatu & 420.7 & 29.8 & 390.9 & 372.5 & 389.7 & -4.72 & -0.32 \\
\hline 5 & Hanjiaying & Yixun & 426.8 & 30.0 & 396.7 & 409.5 & 393.7 & 3.21 & -0.77 \\
\hline 6 & Chengde & Wulie & 503.4 & 62.1 & 441.2 & 444.2 & 452.3 & 0.69 & 2.51 \\
\hline 7 & Xiabancheng & Laoniu & 524.2 & 71.1 & 453.2 & 463.4 & 454.9 & 2.27 & 0.37 \\
\hline 8 & Liying & Liu & 595.3 & 96.6 & 498.6 & 516.0 & 501.0 & 3.47 & 0.47 \\
\hline 9 & Kuancheng & $\mathrm{Pu}$ & 533.5 & 85.7 & 447.7 & 464.4 & 452.5 & 3.72 & 1.07 \\
\hline 10 & Panjiakou & Luan & 430.0 & 45.2 & 384.8 & 395.1 & 381.8 & 2.68 & -0.76 \\
\hline
\end{tabular}

Table 1. Comparison of the long-term water balance simulated by the GBHM and waterenergy balance model.

Notes: (1) $E_{w b b}, E_{f u}, E_{g b h m}$ represent mean values of actual evapotranspiration calculated by long-term water balance, the water-energy balance model and the GBHM model respectively. (2) $R E_{1}$ and $R E_{2}$ are the relative errors of the long-term mean values of actual evapotranspiration calculated using the water-energy balance model and the GBHM model, respectively, comparing with the value estimated by long-term water balance. 
evapotranspiration estimated from the annual precipitation and runoff data by neglecting the change of water storage, simulated by the GBHM model and the water-energy balance model. It can be seen that the values of the actual evapotranspiration by different models are in a good agreement. Considering the value estimated from the long-term water balance by neglecting the change of water storage as the "true value" (which is denoted as the "observation"), the relative error for the simulated annual evaportranspiration are within by both GBHM and water-energy balance model.

\section{Actual evapotranspiration at annual time scale}

In order to understand inter-annual variability and the major controlling factors of catchment evapotranspiration at annual time scale, assuming vegetation condition is unchangeable or changeable and neglecting or consideing the variability of soil water four different conditions are used in the simulation for comparison: (1) using Eq. (4) with the same value of parameter $\mathrm{n}$ for every year in each sub-catchment (denoted as Sim-A1); (2) using Eq. (4) with the different value of parameter $n$ estimated using Eq. (5) according to the vegetation coverage for every year in each sub-catchment( denoted as Sim-A2); (3) using Eq. (8) with the same value of parameter $n$ for every year in each sub-catchment(denoted as Sim-A3); (4) using Eq. (8) with the different value of parameter $n$ estimated using Eq. (5) according to the vegetation coverage for every year in each sub-catchment(denoted as SimA4). Taking average values of the annual evapotranspiration during the simulated period (1980-1991) for each sub-catchment simulated by the water-energy balance model and comparing with the observation, Table 2 shows the relative error. Results show that Sim-A3 and Sim-A4 have a better result than Sim-A1 and Sim-A2, which implies that it is essential to consider inter-annual variability of soil moisture for estimating annual catchment evapotranspiration. Table 2 also shows that catchment annual evapotranspiration is more

\begin{tabular}{cccccc}
\hline \multirow{2}{*}{ NO. } & \multirow{2}{*}{ Gauges } & \multicolumn{4}{c}{ Relative Error $(R E, \%)$} \\
\cline { 3 - 6 } & & Sim-A1 & Sim-A2 & Sim-A3 & Sim-A4 \\
\hline 1 & Guojiatun & -5.17 & -7.71 & -1.32 & -2.60 \\
2 & Boluonuo & -8.11 & 4.39 & -4.02 & 4.20 \\
3 & Sandaohezi & -7.30 & -7.62 & -2.42 & -2.64 \\
4 & Xiahenan & -5.28 & -1.44 & -2.11 & -0.28 \\
5 & Hanjiaying & -7.66 & -1.81 & -3.88 & -0.29 \\
6 & Chengde & -5.59 & 4.78 & -2.04 & 4.42 \\
7 & Xiabancheng & -7.93 & 5.22 & -4.57 & 4.80 \\
8 & Liying & 2.32 & 2.77 & 2.76 & 3.05 \\
9 & Kuancheng & 2.25 & 2.90 & 2.38 & 2.71 \\
10 & Panjiakou & -2.73 & -1.11 & -0.33 & 0.11 \\
\hline
\end{tabular}

Table 2. The annual evapotranspiration simulated by the water-energy balance model with different consideration soil water storage and vegetation

Notes: (1) Sim-A1, Sim-A2, Sim-A3, Sim-A4 represent four conditions in simulation of the annual evaportranspiration, i.e., Sim-A1: neglecting the change of the vegetation and soil water; Sim-A2: neglecting the change of soil water; Sim-A3: neglecting the change of the vegetation; Sim-A4: considering the change of the vegetation and soil water. (2) $R E$ is the relative errors of the mean values of annual actual evapotranspiration calculated using the water-energy balance model. 


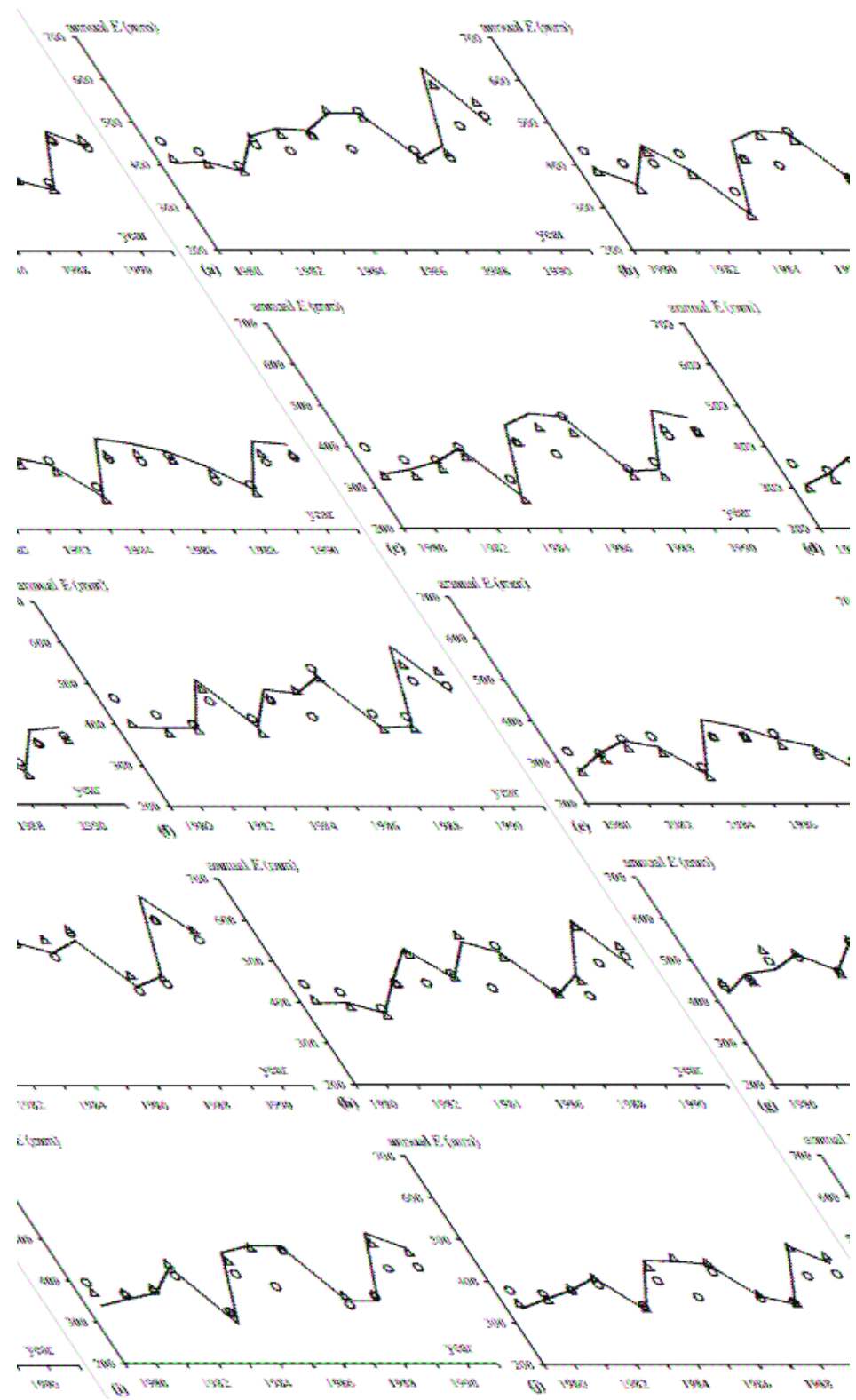

Fig. 7. Comparison of the annual evapotranspiration estimated by the water-energy balance model and GBHM model and the observed one. Figure (a)-(i) represent the 9 subcatchments respectively. Figure (j) represents the whole watershed. (The real lines represent observed annual evapotranspiration (E), the circular dots represent actual annual evapotranspiration $(E)$ predicted by GBHM, and the triangular dots represent actual annual evapotranspiration $(E)$ predicted by water-energy balance model) 
sensitive to the soil water than to the vegetation coverage. Fig. 7 shows the inter-annual variability of the actual evapotranspiration in each sub-catchment from 1980 to 1991 simulated by the water-energy balance model in Sim-A4 (considering inter-annual variability of both vegetation and soil water) and the GBHM model. It can be seen that both results have a very similar temporal pattern for the 10 sub-catchments. Results show that both the simple lumped water-energy balance model and the physically-based distributed hydrological model can predict catchment annual evapotranspiration and its inter-annual variability.

\section{Actual evapotranspiration at monthly time scale}

At monthly time scale, similar assumptions and similar four conditions as the above were used in the simulation of monthly evapotranspiration, i.e., (1) using Eq. (4) with a constant parameter $\mathrm{n}$ for each sub-catchment (denoted as Sim-M1); (2) using Eq. (4) with the different value of parameter $\mathrm{n}$ for every month in each sub-catchment (denoted as Sim-M2); (3) using Eq. (8) with a constant parameter $\mathrm{n}$ in each sub-catchment (denoted as Sim-M3); (4) using Eq. (8) with the different value of parameter $n$ for every month in each sub-catchment (denoted as Sim-M4). Monthly evapotranspiration are integrated to the long-term annual evapotranspiration, which is used to compare with the observation. Table 3 shows the results of the relative error for each sub-catchment. It can be seen that the result of Sim-M4 has the least relative error, which implies that it is essential to include variability of both soil water and vegetation coverage for estimating catchment evapotranspiration at monthly time scale. The results also indicate that the soil water content is more important than the parameter $\mathrm{n}$ for estimating the monthly evapotranspiration. Taking the whole study area as an example, Fig. 8 shows the comparison of the monthly evapotranspiration estimated by Sim-M4 of the water-energy balance model and by the GBHM model. Both results have a

\begin{tabular}{cccccc}
\hline \multirow{2}{*}{ NO. } & \multirow{2}{*}{ Gauges } & \multicolumn{4}{c}{ Relative Error $(R E, \%)$} \\
\cline { 3 - 6 } & & Sim-M1 & Sim-M2 & Sim-M3 & Sim-M4 \\
\hline 1 & Guojiatun & -19.88 & -18.11 & -2.39 & -1.14 \\
2 & Boluonuo & -16.32 & -13.24 & -2.51 & -0.26 \\
3 & Sandaohezi & -20.07 & -17.72 & -4.53 & -2.47 \\
4 & Xiahenan & -16.31 & -13.90 & -5.03 & -2.67 \\
5 & Hanjiaying & -17.30 & -15.10 & -7.71 & -5.52 \\
6 & Chengde & -13.33 & -11.22 & -8.29 & -5.89 \\
7 & Xiabancheng & -15.94 & -13.83 & -3.07 & -2.01 \\
8 & Liying & -14.10 & -8.22 & -4.44 & -1.82 \\
9 & Kuancheng & -12.61 & -10.59 & -5.29 & -3.29 \\
10 & Panjiakou & -15.38 & -12.77 & -4.86 & -2.68 \\
\hline
\end{tabular}

Table 3. The monthly evapotranspiration simulated by the water-energy balance model with different consideration soil water storage and vegetation

Notes: (1) Sim-M1, Sim-M2, Sim-M3, Sim-M4 represent four conditions in simulation the monthly evaportranspiration, i.e., Sim-M1: neglecting the change of the vegetation and soil water; Sim-M2: neglecting the change of soil water; Sim-M3: neglecting the change of the vegetation; Sim-M4: considering the change of the vegetation and soil water. (2) RE is the relative errors of the mean values of annual actual evapotranspiration calculated using the water-energy balance model. 
similar temporal pattern but the highest and lowest peaks estimated by the water-energy balance model are larger/smaller than the peaks calculated by the GBHM model. In Eq. (8), the soil is considered as a single storage with no interaction with the groundwater, and this simplification may be a reason for the error shown in Fig. 8.

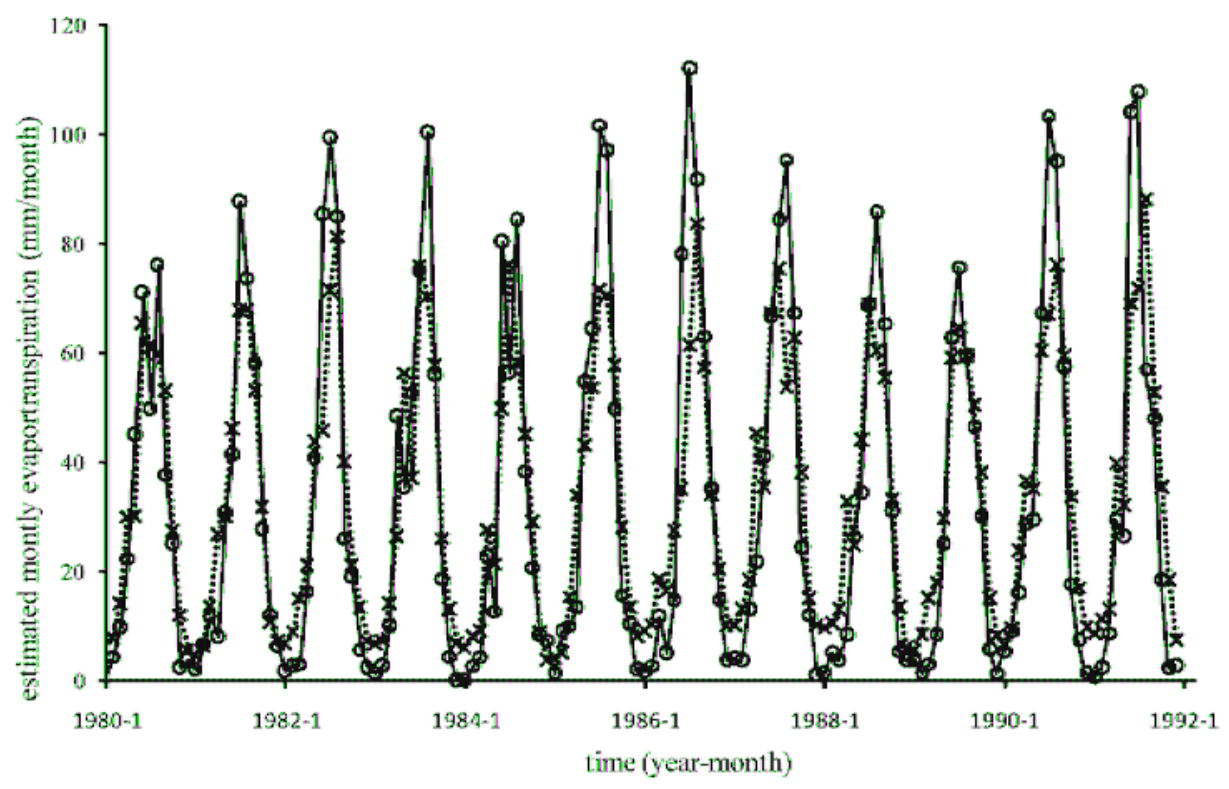

Fig. 8. Comparison of the monthly evapotranspiration estimated by the water-energy balance model and GBHM model for the whole watershed. (The circular real line represents the actual monthly evapotranspiration $(E)$ predicted by water-energy balance model, and the cross dashed line represents the actual monthly evapotranspiration $(E)$ predicted by GBHM)

\section{Actual evapotranspiration at daily time scale}

Since the monthly NDVI data was used in the study, the parameter $\mathrm{n}$ only can be obtained at monthly time scale and the daily parameter $\mathrm{n}$ is considered as the same in each month. At daily time scale, two different conditions are used: (1) neglecting the variability of soil water, which is using Eq. (4) (denoted as Sim-D1) with monthly parameter n; (2) considering the variability of soil water, which is using Eq. (8) (denoted as Sim-D2) with monthly parameter $n$. Daily evapotranspiration is integrated into the long-term mean value of annual evapotranspiration for comparing with the observation. Table 3 shows the relative error for each sub-catchment. It is clear that result of Sim-D2 is much better than the result of Sim-D1, which implies that the soil water content is a very important factor controlling the daily evapotranspiration. Comparing the results simulated at daily time scale by the water-energy balance model and by the GBHM model for the whole study area, it can be seen that the simple water-energy balance model is not possible to simulate the daily variability of evapotranspiration without consideration of the soil moisture storage. However, with consideration of the soil water storage, this simple model is also difficult to capture the daily variability appropriately. As known that soil water movement usually can not penetrate the 
whole soil layer (e.g. 1-m depth) within a day, therefore, it is important to describe the soil water dynamics at daily or shorter time scale rather than to consider a total storage of the soil water.

\section{Conclusions}

In this study a bottom-up and top-down analysis based on a distributed physically-based hydrological model (GBHM) and a simple water-energy balance model derived from Budyko hypothesis was carried out for understanding the dominant factors on catchment evapotranspiration at different scales in 9 sub-cachments and the whole basin of the Luan River in Northern China. At annual and long-term time scales, a consistent result has been achieved by the two models, which show the complementary relationship between the actual and potential evapotranspiration at annual time scale for the study areas. However, at a shorter time scale, the difference between the two simulations by GBHM and the waterenergy balance model became larger. On the basis of the comprehensive inter-comparison in the framework of the top-down and bottom-up analysis through different temporal scales, it can be concluded as follows:

1. The catchment annual water balance pattern can be predicted successfully by both a simple lumped model and a detailed distributed model in the study areas;

2. The relationships between potential and actual evapotranspiration can be different at different temporal and spatial scales. It shows highly nonlinear relationship at annual and catchment scale, but can be simplified as a linear relationship at hourly and hillslope scale;

3. The soil water storage and the soil water dynamics become more important for simulation of evapotranspiration at a shorter temporal scale;

4. Consideration of vegetation coverage can improve the simulation of inter-annual and seasonal variability of catchment evapotranspiration in the lumped water-energy balance model;

5. Comparison of the top-down and the bottom-up methods can offer a new way for understanding the catchment hydrological behavior at different temporal and spatial scales, and is potentially helpful for developing new generation of hydrological model.

\section{Acknowledgement}

This paper was supported by the National Natural Science Foundation of China (Grant No. 50939004).

\section{References}

Abbott M B, Bathurst J C, Cunge J A, O'Connell P E, Rasmussen J(1986), An introduction to the European Hydrological System. SHE, 1: History and philosophy of a physically 2: based distributed modeling system. J. Hydrol. 87, 45 - 59.

Allen, R. G., L. S. Pereira, D. Raes, and M. Smith (Eds.) (1998), Crop Evapotranspiration: Guidelines for Computing Crop Water Requirements. FAO Irrig. and Drainage Paper 56, Rome. 
Arnold, R. Srinivasan, R.S. Muttiah and J.R. Williams (1998), Large area hydrologic modelling and Assessment part I: model development, Journal of the American Water Resources Association. 34 (1), 73 - 89.

Atkinson S, Sivapalan M, Woods RA, Viney NR (2002). Dominant physical controls of hourly streamflow predictions and an examination of the role of spatial variability: Mahurangi catchment, New Zealand. Adv. Water Resour., 26(2), 219 - 235.

Atkinson S, Sivapalan M, Viney NR, Woods RA (2003), Physical controls of space-time variability of hourly streamflows: Mahurangi catchment, New Zealand. Hydrol. Process., 17, 2171 - 2193.

Bathurst, J.M. Wicks and P.E. O'Connell (1995), The SHE/SHESED basin scale water flow and sediment transport modeling system. In Computer Models of Watershed Hydrology, edited by V.P. Singh pp. 563-594. Water Resources Publications, Littleton, $\mathrm{CO}$.

Beven, K. J., Warren, R., Zaoui, J. (1980), SHE: towards a methodology for physically-based, distributed forecasting in hydrology. IAHS Publ. No. 129, Wallingford, UK. 133 137.

Beven, K.J. (2001), How far can we go in distributed hydrological modelling? Hydrology and Earth System Sciences, 5(1), 1-12.

Beven K. (2006), On undermining the science? Hydrological Processes, 20, 3141 - 3146.

Budyko, M. I. (Ed.) (1974), Climate and Life, translated from Russian by Miller, D. H., Academic, San Diego, Calif..

Bouchet, R. (1963), Evapotranspiration reelle et potentielle, signification climatique, Int. Assoc. Sci. Hydro. Pub., 62, 134-142.

Choudhury, B. J. (1999), Evaluation of an empirical equation for annual evaporation using field observations and results from a biophysical model, J. Hydrol., 216, 99 - 110.

Cong, Z., D. Yang, B. Gao, H. Yang, and H. Hu (2009), Hydrological trend analysis in the Yellow River basin using a distributed hydrological model, Water Resour. Res., 45, doi:10.1029/2008WR006852.

Eder G, Sivapalan M, Nachtnebel H.P. (2003), Modeling of water balances in Alpine catchment through exploitation of emergent properties over changing time scales. Hydrol. Process., 17 (11): 2125-2149.

Farmer, D., M. Sivapalan, and C. Jothityangkoon (2003), Climate, soil, and vegetation controls upon the variability of water balance in temperate and semiarid landscapes: Downward approach to water balance analysis, Water Resour. Res., 39(2), 1035, doi:10.1029/2001WR000328.

FAO (2003), FAO Map of World Soil Resources, Rome.

$\mathrm{Fu}$, B. P. (1981), On the calculation of the evaporation from land surface, Scientia Atmospherica Sinica, 5 (1), 23 - 31 (in Chinese).

Gutman, G., and A. Ignatov (1998). The derivation of the green vegetation fraction from NOAA/AVHRR data for use in numerical weather prediction models, International Journal of Remote sensing, 19, 1533 - 1543.

IGBP-DIS (Global Soil Data Task: Global Soil Data Products CD-ROM ) (2000), International Geosphere-Biosphere Programme - Data and Information Services. Available online at (http://www.daac.ornl.gov/) from the ORNL Distributed Active Archive Center, Oak Ridge National Laboratory, Oak Ridge, Tennessee, U.S.A.. 
Jia, G. Ni, Y. Kawahara and T. Suetsugi (2001), Development of WEP model and its application to an urban watershed, Hydrol. Process. 15(11), 2175 - 2194.

Jothityangkoon C, Sivapalan M, Farmer D. (2001). Process controls of water balance variability in a large semi-arid catchment: downward approach to hydrological model development. J. Hydrol., 254(1-4): 174 - 198.

Klemes, V. (1983). Conceptualization and scale in hydrology. J. Hydrol., 65: 1-23.

Kite, G. W. (1995), The SLURP model, In Computer Models of Watershed Hydrology, edited by V. P. Singh. Water Resources Publications, Highlands, CO.

Liang, X. (1994), A two-layer variable infiltration capacity land surface representation for general circulation models. In: Water Resour. Ser. TR140, Univ. Washington, Seattle.

Littlewood, B.F.W. Croke, A.J. Jakeman and M. Sivapalan(2003), The role of 'top-down' modelling for Prediction in Ungauged Basins (PUB), Hydrol. Process., 17, 1673 1679.

Milly, P. C. D. (1994), Climate, soil water storage, and the average annual water balance, Water Resour. Res., 30, 2143 - 2156.

Morris, E.M. (1980), Forecasting flood flows in grassy and forested basins using a deterministic distributed mathematical model. IAHS Publ. No.129, 247 - 265.

New, M., M. Hulme and P. Jones (2000), Representing twentieth-century space-time climate variability. Part II: Development of a 1961-96 monthly grids of terrestrial surface climate, Journal of Climate, 13, 2217-2238.

Penman, H. L. (1948), Natural evaporation from open water, bare and grass. Proc. R. Soc. Lond., Ser. A 193, 120 - 145.

Refsgaard J.C. and Storm B. (1995), MIKE SHE. In Computer Models of Watershed Hydrology, edited by V. P. Singh. pp. 809-846. Water Resources Publications, Highlands, CO.

Shuttleworth, W. J., (1993), Evaporation. In Handbook of Hydrology, edited by D. R. Maidment, pp.4.1 - 4.53. McGraw-Hill, New York.

Sivapalan M, Blöschl G, Zhang L, Vertessy R. (2003), Downward approach to hydrological prediction. Hydrol. Process., 17, 2101-2111.

Sivapalan M. (2009), The secret to 'doing better hydrological science': change the question! Hydrological Processes, 23, 1391 - 1396.

Sivakumar, B. (2008), Undermining the science or undermining Nature? Hydrologial Processes, 22, 893 - 897.

Son, K. and Sivapalan, M. (2007), Improving model structure and reducing parameter uncertainty in conceptual water balance models through the use of auxiliary data. Water Resour. Res., 43: W01415, doi: 10.1029/2006WR005032.

Sun, F.B., Yang D.W., Liu Z.Y., Cong Z.T., Lei Z.D. (2007), Validation of Coupled waterenergy balance in the Haihe River basin and inland river basins, Journal of China Hydrology, 27(2),7-10 (in Chinese).

Wolock, D. M., and G. J. McCabe (1999), Explaining spatial variability in mean annual runoff in the conterminous United States, Clim. Res., 11, 149 - 159.

Xu, J., D. Yang, J. Ding, Z. Lei (2007), Development of space-nested watershed hydrological model and its application to floods forecasting of Three Gorges reservoir. Journal of Hydraulic Engineering, S1, 365 - 371 (in Chinese).

Xu, J., D. Yang*, Z. Lei, J. Chen and W. Yang (2008), Spatial and temporal variation of runoff in the Yangtze River basin during the past 40 years. Quaternary International, 186: 32-42, doi:10.1016/j.quaint. (SCI) 
Yang, D., S. Herath, and K. Musiake (1998), Development of a geomorphology-based hydrological model for large catchments, Annual Journal of Hydraulic Engineering, JSCE, 42, 169-174.

Yang D, Oki T, Herath S, Musiake K. (2002), A geomorphology-based hydrological model and its applications. In Mathematical Models of Small Watershed Hydrology and Applications, edited by Singh VP, Frevert DK. Water Resources Publications: Littleton, CO; 259-300.

Yang, D., C. Li, H. Hu, Z. Lei, S. Yang, T. Kusuda, T. Koike, and K. Musiake, (2004), Analysis of water resources variability in the Yellow River of China during the last half century using historical data, Water Resour. Res., 40, W06502, doi:10.1029/2003WR002763.

Yang, D., F. Sun, Z. Liu, Z. Cong, and Z. Lei (2006), Interpreting the complementary relationship in non-humid environments based on the Budyko and Penman hypotheses. Geophys. Res. Lett., 33, L18402, doi: 10.1029/2006GL027657.

Yang, D., F. Sun, Z. Liu, Z. Cong, G. Ni and Z. Lei (2007), Analyzing spatial and temporal variability of annual water-energy balance in non-humid regions of China using the Budyko hypothesis. Water Resour. Res., 43, W04426, doi: 10.1029/2006WR005224.

Yang, D., W. Shao, P. J.-F. Yeh, H. Yang, S. Kanae, and T. Oki (2009), Impact of Vegetation Coverage on Regional Water Balance in the Non-Humid Regions of China, Water Resour. Res., doi:10.1029/2008WR006948.

Yang, H., D. Yang, Z. Lei, and F. Sun (2008a), New analytical derivation of the mean annual water-energy balance equation, Water Resour. Res., 44, W03410, doi: 10.1029/2007WR006135.

Yang, H., D. Yang, Z. Lei, and H. Lei (2008b), Derivation and verification of the coupled water-energy balance equation at arbitrary time scale, Journal of Hydraulic Engineering, 39 (5), 610 - 617 (in Chinese).

Zhang, L., K. Hickel, W. R. Dawes, F. H. S. Chiew, A. W. Western, and P. R. Briggs (2004), A rational function approach for estimating mean annual evapotranspiration, Water Resour. Res., 40, W02502, doi: 10.1029/2003WR002710.

Zhang, L., N. Potter, K. Hickel, Y.Q. Zhang, Q.X. Shao (2008), Water balance modeling over variable time scales based on the Budyko framework - Model development and testing, Journal of Hydrology, 360(1-4), 117-131. 


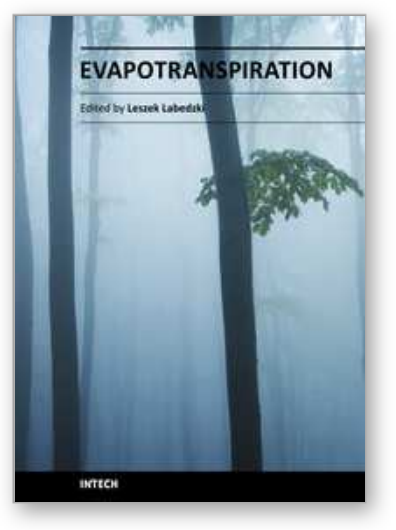

\author{
Evapotranspiration \\ Edited by Prof. Leszek Labedzki
}

ISBN 978-953-307-251-7

Hard cover, 446 pages

Publisher InTech

Published online 16, March, 2011

Published in print edition March, 2011

Evapotranspiration is a very complex phenomenon, comprising different aspects and processes (hydrological, meteorological, physiological, soil, plant and others). Farmers, agriculture advisers, extension services, hydrologists, agrometeorologists, water management specialists and many others are facing the problem of evapotranspiration. This book is dedicated to further understanding of the evapotranspiration problems, presenting a broad body of experience, by reporting different views of the authors and the results of their studies. It covers aspects from understandings and concepts of evapotranspiration, through methodology of calculating and measuring, to applications in different fields, in which evapotranspiration is an important factor. The book will be of benefit to scientists, engineers and managers involved in problems related to meteorology, climatology, hydrology, geography, agronomy and agricultural water management. We hope they will find useful material in this collection of papers.

\title{
How to reference
}

In order to correctly reference this scholarly work, feel free to copy and paste the following:

Xiangyu Xu and Dawen Yang (2011). Analysis of Catchment Evapotranspiration at Different Scales Using Bottom-up and Top-down Approaches, Evapotranspiration, Prof. Leszek Labedzki (Ed.), ISBN: 978-953-307251-7, InTech, Available from: http://www.intechopen.com/books/evapotranspiration/analysis-of-catchmentevapotranspiration-at-different-scales-using-bottom-up-and-top-down-approaches

\section{INTECH}

open science | open minds

\section{InTech Europe}

University Campus STeP Ri

Slavka Krautzeka 83/A

51000 Rijeka, Croatia

Phone: +385 (51) 770447

Fax: +385 (51) 686166

www.intechopen.com

\section{InTech China}

Unit 405, Office Block, Hotel Equatorial Shanghai

No.65, Yan An Road (West), Shanghai, 200040, China 中国上海市延安西路65号上海国际贵都大饭店办公楼 405 单元 Phone: +86-21-62489820

Fax: $+86-21-62489821$ 
(C) 2011 The Author(s). Licensee IntechOpen. This chapter is distributed under the terms of the Creative Commons Attribution-NonCommercialShareAlike-3.0 License, which permits use, distribution and reproduction for non-commercial purposes, provided the original is properly cited and derivative works building on this content are distributed under the same license. 